\title{
The Effects of Implicit and Explicit Instruction on Foreign Language Learners' Working Memory Capacity and L2 Grammatical Knowledge
}

\author{
Roya Khoii, Newsha Ahmadi, Shaghayegh Sharbati \\ Islamic Azad University, North Tehran Branch
}

\begin{abstract}
This study investigated the role of implicit and explicit grammar instruction on expanding working memory capacity (WMC) and improving L2 grammatical knowledge. The participants were 30 L2 learners equally divided into two experimental classes. Before the treatment, a grammar pretest was used to measure their grammatical knowledge, and three tests (Forward Digit Span Test, Paired Associates Test, Operation Span Test) were used to measure their WMC. During the treatment, the explicit group studied grammar using the guided discovery, text-based teaching, and explicit feedback techniques, and the implicit group did so using textual enhancement, input flood, and implicit feedback techniques. At the end of the experiment, the same grammar test and WMC tests were used as posttests to check the effects of the treatments. The results showed that the implicit group had significantly outperformed the explicit group on WMC tests, while no such difference was observed between their grammar posttest scores.
\end{abstract}

\section{Introduction}

The learning and use of a foreign language draws upon a wide range of cognitive processes. One process receiving increasing attention today is working memory. According to Baddeley, working memory (WM) is the ability to mentally store and manipulate information relevant to a task in the course of ongoing processing [1]. Many comprehensive studies have been conducted on the impact of working memory capacity (WMC) on developing different language skills, such as reading comprehension, writing, listening, and speaking, and language sub-skills, such as vocabulary, grammar, and pronunciation [2]. Moreover, a large body of research has been recently carried out to investigate WMC expansion, WMC and its limitations, and WMC assessment.

Hermann Ebbinghus [3, p.9] was the first one who performed the first systematic studies of memory in the $19^{\text {th }}$ century. Then James [3, p.13] made a distinction between long-term memory and working memory, which he called primary and secondary memory. Later, Miller [3, p.13], a cognitive psychologist, provided a detailed account of the limited capacity of the short-term storage. In his article, The Magical Number Seven, he declared that people can store seven (plus or minus two) items in their minds [3]. Atkinson and Shiffrin [4, p.14] proposed that there are two distinct modes of storing information in their model, the short-term memory serves as a gateway to store the incoming input, and then the input goes to long-term memory for further processing. However, today this model does not have the effect of that time because most experts favor a more dynamic role for the short-term memory than storing alone. This shift has been reflected in the increasing use of the term Working Memory (WM).

Previous findings have shown that WM plays a vital role in language learning. It is a passageway to long-term memory (LTM), whose span determines the extent of information therein. However, because of the limited capacity of WM, the amount of information and the longevity of its existence depends upon WM span [4]. Historically, it was believed that WM is a heritable construct and is resistant to change, but recent research has affirmed that WM is malleable [5]. It has been suggested that WMC can be expanded by different cognitive, interactive, and computerized tasks, such as repetition, memorization with consciousness, chunking, and the use of multimedia [6]. Moreover, it is generally believed that individuals with higher WM capacities are better in performing different cognitive tasks. Obviously, language learning, particularly, foreign language learning, is a cognitive process that relies mostly, if not solely, on WMC [7].

Research findings indicate that individuals with a higher level of WMC are better in different facets of 
language learning activities. For instance, Daneman and Carpenter [3, p. 50] studied the relationship between reading comprehension and WMC. They found out that those with a higher level of WMC are better comprehenders. Kane and Eagle $[3$, p. 50] reported that individuals with a higher WMC performed the Stroop Task better than the students with a lower WMC. Kane, Bleckley, Conway and Engle [3, p. 50] administered an antisaccade task and found that a higher WMC can contribute to identifying the right answers when the wrong stimulus is in hand [3]. All things being equal, according to Nielson [8], learners with low WMC are at a disadvantage when compared to learners with high WMC in the course of second language learning.

Previous studies primarily focused on the impact of WM on vocabulary learning, fluency development, reading comprehension, and the learning of grammatical knowledge. Their findings report the existence of a consistent relationship between WM and grammar learning [9].

On the other hand, the past decades have seen a sudden increase in the amount of quasi-experimental and experimental studies that address the effectiveness of two important types of grammar instruction in L2 classrooms called explicit grammar instruction and implicit grammar instruction [10]. Evidently, one of the controversial issues in grammar instruction is the difference between implicit and explicit teaching or Focus on From versus Focus on Forms approaches to grammar teaching.

In spite of the abundance of independent studies on grammar instruction and WMC, not much research has been carried out on the impact of grammar instruction on WMC expansion. Therefore, the present study was set out to investigate the impact of two grammar instruction methods, implicit and explicit, on increasing FL learners' WMC and grammatical knowledge.

\section{Working memory}

As Bilbrough (2011) noted, "There is no learning without remembering. And language learningperhaps more than most forms of learning- places huge demands on memory". This is a widely accepted idea that the mind and language are closely intertwined, and the study of language in human beings is not separated from the study of the mind and the brain [4].

For many years, one of the main concerns in language teaching has been individual differences. One of these individual differences is the notion of working memory and its effects on language teaching and learning. According to Juffs and
Harrington [1], working memory refers to the mental processes responsible for the temporary storage and manipulation of information while performing higher order tasks, such as reasoning, problem solving, and comprehension. It is not a memory per se, if by that term it means the capacity to store the information. Rather, it is a system to control the attention.

Working memory is used in everyday cognition from keeping a point in mind when listening to someone else to calculating a tip in a restaurant, remembering the directions while driving, and parsing complex sentences. It is, in fact, the fundamental construct of individual differences in a wide range of cognitive tasks.

There are a variety of models describing how working memory functions. However, as mentioned before, the most widely accepted one seems to have been proposed by Baddeley and Hitch (Figure 1) [11].

\section{(a)}

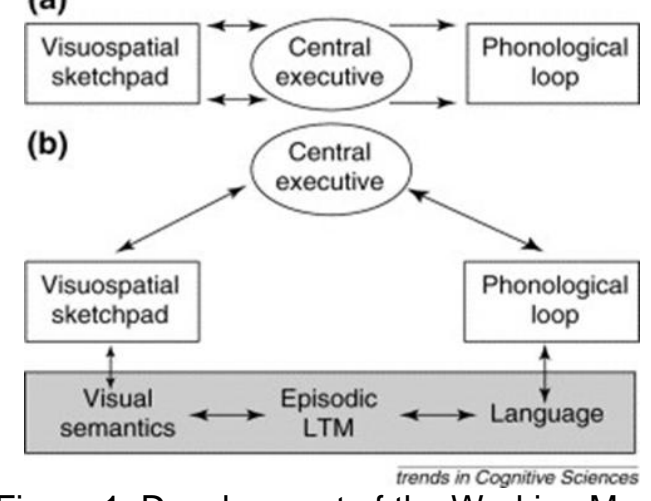

Figure 1. Development of the Working Memory Model (Baddeley and Hitch, 1974)

This model consists of three components including: central executive, visuospatial sketchpad, and the phonological loop (PL), with the last two considered to be the slave systems. After revising this model several times, Baddeley added another slave system to it called the episodic buffer [4]. The central executive or the supervisory attentional system (SAS) controls the attention, directs the attention to relevant information and suppresses the irrelevant information, and is used for coordinating cognitive processes when more than one task must be done simultaneously [4]. The phonological loop (PL) is responsible to hold phonological representation for a brief period of about 2 seconds [2]. The visuospatial sketchpad is dedicated to visual or spatial memory, which temporarily maintains and manipulates visuospatial information [1]. The episodic buffer integrates phonological, visual, and spatial information. This component is episodic because it is assumed to bind information into a unitary episodic representation [4]. 
In recent decades, there has been a large body of research on the role of WM and its capacity in various disciplines, including psychology, neuropsychology, cognitive psychology, social sciences, and language learning/teaching. As the researchers inquiring into the impact of WMC on language learning have maintained, this capacity is limited, and this limitedness can be interpreted in terms of digits, letters, or chunks. Whatever scale we use to interpret this capacity, it is assumed to be between 5-9 digits or chunks. The limited capacity of WM makes it difficult for the SLL/FLL learners to pay attention to the top-down and bottom-up factors involved in decoding and encoding meaning. The researchers argue that it would be beneficial for learners to pay attention to the top-down factors from early stages, since this process makes the comprehension of texts much easier [4]. The restricted capacity of the WM places a huge burden on second language learners who have to use this limited capacity to decode the language as well as manipulate the meaning and combine the new input to that already received. Here, the roles of noticing and the central executive become more salient in the discussions related to second/foreign language learning and WMC.

Studies examining individual differences in working memory capacity have suggested that individuals with low working memory capacities demonstrate impaired performance on a variety of attention and memory tasks compared with individuals with high working memory capacities.

Regarding the effects of WMC on various facets of language activities, it has been reported that those with a higher level of WMC have a higher level of reading comprehension. The same relationship has also been demonstrated between grammar and WMC. O'Brien et al. [12] maintain that the phonological loop (PL) plays an important role in narrative development at earlier stages of L2 learning and in the acquisition of grammatical competence at later stages. Martin and Ellis [13] studied the relationship between PL and WM, on the one hand, and grammar and vocabulary learning, on the other, in an artificial foreign language. The results showed the significant independent effects of PL and WM on L2 vocabulary and grammar learning. They concluded that both grammar and vocabulary involve the memorization of phonological sequences in PL, but grammatical patterns are more complicated to process, so they are more likely to be reliant on WM. Ercetin and Alptekin [14] conducted another study which explored the relationships between second language (L2) explicit/implicit knowledge sources and working memory capacity. They further examined the relationships between L2 reading comprehension and WMC as well as between L2 reading comprehension and L2 explicit/implicit knowledge sources. The results suggested that WM is able to manipulate and store both explicit and implicit L2 input through controlled and automatic processes. It has also been suggested that L2 explicit knowledge, connected with the control processes of the declarative system's lexical/semantic features and L2 WM, reflecting attentional resource capacity associated with control processes, play an important role in L2 reading comprehension, whereas implicit L2 knowledge forms an independent factor with no relationship to L2 reading comprehension.

\section{Assessing working memory capacity}

One of the concerns regarding WM is how it can be measured. Working memory capacity is determined by both simple storage and processing components, which can be estimated separately or in combination. The number of unrelated words or digits that can be recalled can measure simple shortterm storage capacity. Processing capacity is measured using tasks that make simultaneous demand on both storage and processing, sometimes referred to as complex WM [1]. The most famous of these tests are Forward digit span and Nonword repetition/recognition for simple short-term storage capacity, and Reading span test and Operation test task for processing capacity [15]. Recently, researchers have used a novel form of test which measures the different parts of WM separately. Thompson [16] used Lucid Recall, which measures the phonological loop, visuospatial, and executive control separately. It is done because the different parts of the working memory are responsible for different kinds of learning. For instance, PL has been associated with vocabulary learning and also shares links with mathematical problem solving. The visuospatial sketchpad has been related to arithmetic and mathematics, and the central executive has been associated with learning and attainment across a number of domains, including syntax and reading development, arithmetic and mathematical performance, and overall academic attainment [16].

Some studies show that the amount of WMC varies from one learner to another, and it can be about 3-5 chunks. These variations relate to individuals' success in different fields because learners with higher WMC demonstrate more noticing during different cognitive tasks, especially language learning. In other words, WM and its span play a crucial role in many cognitive tasks, especially tasks that need attention. 


\section{Explicit versus implicit grammar instruction and working memory}

Perhaps, no term in the field of language teaching is as ambiguous as grammar [17].Traditionally grammar teaching was narrowly defined as the presentation of discrete grammatical rules to learners. Ellis [18] provides a broad definition of grammar as follows: "Grammar teaching involves any instructional technique that draws learners' attention to some specific grammatical form in such a way that it helps them either to understand it metalinguistically and/or process it in comprehension and/or production so that they can internalize it."

This definition makes it quite clear that grammar teaching can be carried out by different methods, such as through rule presentation, encouraging learners to discover the grammatical rules by themselves, providing them with multiple exemplars of the target structure as input, and providing the learners with corrective feedback regarding their production [19].

Grammar is pivotal for language learning [9]. Without grammar, language does not exist. Nevertheless, the discussion about grammar has always been a controversial issue, and this controversy has been whether grammar should be taught explicitly through the formal presentation of grammatical rules or implicitly through natural exposure to meaningful language use.

The idea that language can be learned without some degree of consciousness has been found problematic. Additionally, there is ample empirical evidence that teaching approaches that focus on meaning with no focus on grammar are inappropriate. Thirdly, it is a widely accepted idea that instructed language learning has major effects on L2 acquisition. Particularly, research has demonstrated that form-focused instruction is effective when it is incorporated into meaningful contexts [9]. Hence, there are still many unanswered questions about how grammar can be taught and learned much more effectively.

Research on foreign language acquisition over the past decades has seen a proliferation of various studies that address the effectiveness of two important types of grammar instruction in L2 classrooms called explicit grammar instruction and implicit grammar instruction [18]. Interestingly, children acquire their first language implicitly through natural exposure to their mother tongue; hence, they automatically acquire the complex knowledge of the structure of their language. On the contrary, adult learners tend to learn second/foreign languages explicitly. As a result, adult attainment of L2 accuracy usually requires additional resources of consciousness and explicit learning [18]. The core issue in implicit and explicit teaching is the notion of noticing. Schmit [18] has distinguished between two types of awareness: awareness as consciousness and awareness as noticing. Awareness as noticing can be categorized into two types, namely, noticing as in perception and metalinguistic awareness (analysis). The former involves conscious attention to 'surface elements', whereas the latter involves awareness of the underlying abstract rule that governs particular linguistic phenomena. Implicit learning means learning without conscious metalinguistic awareness, while explicit learning is necessarily a conscious process and is generally intentional as well. It is conscious learning "where the individual makes and tests hypotheses in a search for structure" [14]. As a result, the notion of noticing and the control of attention play a significant role in the discussions related to WM [4].

Explicit instruction attracts learners' attention to form and involves direct intervention, whereas implicit instruction is directed at enabling learners to infer rules without awareness [18]. Different techniques are used in each of these methods; for example, using meta-language, encouraging guided discovery [20], and text-based learning techniques are examples of explicit grammar teaching. On the other hand, input-enhancement, context-build, input flood, and implicit feedback are among the techniques used in implicit grammar instruction [3] and [18].

Within the discussions related to implicit and explicit learning and teaching, the notions of Focus on Forms and Focus on Form have gained enough saliency to occupy the minds of FLL researchers. According to Long [4, p.157], there are three basic teaching options: a) Focus on Meaning: by providing a rich corpus of appropriate language material; b) Focus on FormS: by studying formal aspects of the language such as grammar in isolation; c) Focus on Form: by using student output to provide examples of language form which will help them to communicate more effectively in the future, thus integrating meaning and form. It is believed that Focus on Form raises the learners' attention to the form more than the other approaches. Consequently, the central executive will become more active and suppress the irrelevant information. Obviously, the more the central executive is trained, the more WM is activated. In this sense, the information will be transferred to the LTM faster and will remain there for a longer time.

A great deal of controversy in the teaching of grammar can be ascribed to the general issue of whether an explicit or implicit approach to teaching structure is best. Norris \& Ortega [10] conducted a 
meta-analysis investigating the effects of these two types of instruction. Their implicit instruction consisted of either enriched input or a set of sentences containing the target feature which the learners were simply asked to memorize, and their explicit instruction involved metalinguistic explanation. They reported that the students in explicit classes had outperformed those in the implicit ones. Spada [21] also affirms that explicit form-focused instruction is more effective than implicit form-focused instruction in communicative and content-based classrooms.

Noticing plays a crucial role in the discussions related to both implicit and explicit grammar instruction and WMC. As mentioned before, implicit teaching takes place with no awareness, whereas explicit teaching is a process which needs attention [18]. On the other hand, WM, particularly the central executive, is responsible for controlling attention. Therefore, the central executive has the responsibility to notice the significant features in the input. The degree to which noticing can best be achieved is the center of much SLA research at the moment [4].

Obviously, grammar rules place too great a memory load on the learner. Approaches to grammar which involve noticing rather than naming of patterns are likely to be more successful [4]. Consequently, it is believed that Focus on Form (implicit teaching of grammar in context) places a smaller burden on WM because learners naturally receive the comprehensible input without any conscious awareness, whereas the traditional Focus on Forms (explicit grammar teaching out of context) relies heavily on WM because learners have to consciously notice a great deal of information which they should receive and decode by means of their limited WM capacity [6].

Much of the research that has focused on WM in grammar learning involves explicit learning conditions with relatively little attention to implicit or naturalistic learning conditions [13]. As a result, this study was mainly conducted to investigate which teaching condition, implicit/explicit grammar instruction, can possibly contribute to the expansion of EFL learners' WMC. A secondary purpose here was also to check which of these two methods could help them improve their knowledge of grammar more successfully.

\section{Research questions}

This study aimed at answering the following questions:
- Do implicit and explicit types of grammar instruction affect EFL learners' working memory span?

- Do implicit and explicit methods of grammar instruction affect EFL learners' grammatical knowledge differently?

\section{Method}

This section provides the required information concerning the participants, instruments, and the procedure of the study.

\subsection{Participants}

A total number of 30 male and female preintermediate EFL learners studying English in an English language institute in Tehran participated in this study. They were between 13 and 23 years of age. The participants were selected from two intact classes which were randomly assigned to two experimental groups. One class received implicit grammar instruction, and the other class received explicit grammar instruction. All the students had two years' experience of studying English.

\subsection{Instruments}

The following instruments were used to achieve the purposes of this study:

a. A teacher-made achievement test consisting of 75 multiple-choice grammar, vocabulary, and reading comprehension items to homogenize the students in terms of language proficiency.

a. A grammar pretest similar to the grammar section of the homogenizing test used to measure the participants' knowledge of grammar before the treatment.

b. The Forward Digit Span online test available on www.Cambridgebrainsciences.com used both as a pretest and as posttest to measure the participants' phonological loop.

c. The Paired Associates online test available on www.Cambridgebrainsciences.com used as both a pretest and posttest to measure the participants' visuospatial sketchpad.

d. The Operation Span Test (Turner \& Engle, 1989; Sanz et al. 2010) used as both a pretest and posttest to measure the participants' central executive. 


\subsection{Procedure}

At the outset of the study, a teacher-made achievement test was given to 40 male and female pre-intermediate EFL learners studying English in an English language institute in Tehran to choose a homogenous sample. After correcting the papers, their scores were statistically analyzed and, based on the results, 30 of the students were chosen as the ultimate participants of the study. They were later randomly divided into two experimental groups. To ensure that there was no statistically significant difference between the two groups regarding their grammatical knowledge and WMC, a grammar test and a series of WM tests as pretests were administered to both groups. According to Thompson [16], different components of WM are responsible for different domains of learning; therefore, the subcomponents of working memory should be assessed using a range of measures as follows: Forward Digit Span (to measure the phonological loop), Paired Associate (to measure the visuospatial sketchpad), and Operation Span Test (to measure the central executive). The whole process of research was carried out during a 16-session semester. The first two sessions and the last two sessions were devoted to administering the related tests. During the 12 treatment sessions, 8 grammatical features were taught to both groups.

In the explicit group, grammar was taught employing the text-based, guided discovery [19], and explicit feedback techniques in order to direct the students' attention to form. The teacher began with a reading text or a listening extract to set the context. Then the students were exposed to some examples from the previously studied reading or listening texts. The examples were presented through PowerPoint slides. Next, the students were asked to answer some questions on form, function, and an integration of function and form in the related forms in order to discover the rules themselves. Later, the teacher explained the rules to them in order to make sure that they had inferred the correct rule.

In the second class, grammar was taught implicitly using the input enhancement, input flood, and implicit feedback techniques. Here, the slides were designed to attract the learners' attention to the target grammatical points through enhancing the input by bolding, underlying, coloring, and italicizing. There was no direct explanation by the teacher. The procedure in both classes included the employment of some controlled and free types of practice. At the end of the study, the same WMC tests and another achievement grammar posttest were given to the students in both groups to measure the potential changes in their WMC and grammatical knowledge.

\section{Results}

In order to check the effects of the treatments, the collected data were submitted to several statistical analyses. First, a thorough process of item analysis was run for the homogenizing test. After calculating $\mathrm{B}$-indices and difference indices (DI) for all the items, the poor items were identified and discarded. Then all the papers were rescored and the related descriptive statistics were computed (Table 1).

Table 1. Descriptive statistics for the grammar tests

\begin{tabular}{|l|c|c|c|}
\hline \multicolumn{1}{|c|}{ Tests } & N & M & SD \\
\hline Homogenizing test & 30 & 36.66 & 8.9 \\
\hline I Group pretest & 30 & 15.73 & 4.74 \\
\hline I Group posttest & 30 & 22.16 & 3.50 \\
\hline E Group pretest & 15 & 15.33 & 5.13 \\
\hline E Group posttest & 15 & 16.26 & 3.76 \\
\hline
\end{tabular}

I Group = implicit group

E Group $=$ explicit group

Later the reliability of the whole test was calculated using the Threshold Loss Agreement Formula (.80, which was satisfactory). The same process was followed for both the grammar pretest and posttest. Their calculated reliability quotients were equal to .75 and .95 , respectively, which were also satisfactory. Moreover, the content validity of the test was examined by having two experienced professors judge the level of conformity between the table of specifications of the test and the table of contents of the books. They confirmed that the test was a representative sample of the contents of the students' two previous course books and was at the right level of difficulty. Therefore, the researchers felt safe in employing the above test for the participant selection process of this study.

The descriptive statistics of both pre and post WMC tests were also computed (Table 2) 
Table 2. Descriptive statistics of pre and post WMC tests

\begin{tabular}{|c|c|c|c|c|c|c|}
\hline \multirow{9}{*}{ I } & Tests & $\mathbf{N}$ & $M$ & Std. & Min & Max \\
\hline & PL pretest & 15 & 4.93 & 1.10 & 3 & 7 \\
\hline & PL posttest & 15 & 7.27 & 1.33 & 5 & 9 \\
\hline & OPI pretest & 15 & 3.07 & 1.53 & 0 & 5 \\
\hline & OPI posttest & 15 & 6.40 & 1.35 & 4 & 9 \\
\hline & $\begin{array}{l}\text { visuospatial } \\
\text { pretest }\end{array}$ & 15 & 5.27 & 0.96 & 4 & 7 \\
\hline & $\begin{array}{l}\text { visuospatial } \\
\text { posttest }\end{array}$ & 15 & 7.13 & 1.35 & 5 & 9 \\
\hline & WM pretest & 15 & 13.4 & 3.06 & 8 & 18 \\
\hline & $\begin{array}{l}\text { WM } \\
\text { posttest }\end{array}$ & 15 & 19.6 & 2.99 & 13 & 24 \\
\hline \multirow{8}{*}{$\mathrm{E}$} & PL pretest & 15 & 5.27 & 0.59 & 4 & 6 \\
\hline & PL posttest & 15 & 6.47 & 0.51 & 6 & 7 \\
\hline & OPI pretest & 15 & 3.80 & 1.65 & 0 & 6 \\
\hline & PL posttest & 15 & 5.20 & 0.86 & 4 & 6 \\
\hline & $\begin{array}{l}\text { visuospatial } \\
\text { pretest }\end{array}$ & 15 & 4.67 & 1.04 & 3 & 7 \\
\hline & $\begin{array}{l}\text { visuospatial } \\
\text { pretest }\end{array}$ & 15 & 5.27 & 0.70 & 4 & 7 \\
\hline & WM pretest & 15 & 13.33 & 2.12 & 9 & 17 \\
\hline & $\begin{array}{l}\text { WM } \\
\text { posttest }\end{array}$ & 15 & 16.93 & 1.58 & 14 & 19 \\
\hline \multicolumn{7}{|c|}{$I=$ Implicit group } \\
\hline \multicolumn{7}{|c|}{$E=$ explicit group } \\
\hline \multicolumn{7}{|c|}{$P L=$ Phonological loop test } \\
\hline \multicolumn{7}{|c|}{ Visuospatial = Visuospatial sketchpad test } \\
\hline
\end{tabular}

After administering and scoring the homogenizing test, a grammar pretest was administered in order to determine the participants' grammar knowledge before the treatment. With $\mathrm{F}(2,28)=1.710, p=0.575$ (two-tailed), it was decided that the variances of the two groups on the grammar pretest were homogenous. Later, an independent sample t-test was run to ensure that there was no statistically significant difference between the means of the two groups on the grammar pretest prior to the treatment. With $\mathrm{t}(28)=0.56, p=.575$ (two-tailed), it was concluded that the mean difference between the two groups was not significant. Hence, the two groups belonged to the same population at the outset of the experiment.

In the next phase of the study, a series of WMC pretests were administered in order to measure the participants' WM span before the treatments. This would enable the researcher to investigate the possible impact of the treatments on the expansion of the participants' WMC. Further, a series of Levene's tests and independent samples t-tests were run to compare the variances and means of the two groups on the measures of WMC before the treatment (Table 3). With $\mathrm{F}(2,28)=1.676, p=0.206$ (twotailed) for the PL test; $\mathrm{F}(2,28)=.003 p=.957$ (twotailed) for the OPI test; $\mathrm{F}(2,28)=.020 p=.889$ (twotailed) for the visuospatial test, and $\mathrm{F}(2,28)=3.809$ $p=.061$ (two-tailed) for the total WM test, it was decided that the variances of the scores of the two groups were homogenous. Additionally, the results in Table 3 indicate that, with $\mathrm{t}(28)=1.03, p=.31$ (two-tailed) for the PL pretest; $\mathrm{t}(28)=1.25, p=.21$ (two-tailed) for the OPI pretest; $\mathrm{t}(28)=1.63, p=$ .11 (two-tailed) for the visuospatial sketchpad pretest, and $\mathrm{t}(28)=.069, p=.94$ (two-tailed) for the total WM pretest, it was concluded that the two groups belonged to the same population prior to the treatment. In other words, there were no significant differences between the mean scores of the two groups on any of the components of WMC and the grammar pretests at the outset of study.

At the end of the treatment, a series of WMC tests similar to the pretests were administered to the two groups to investigate the changes in the participants' WM span. Once more, a series of Levene's tests and independent samples t-tests were run to explore the homogeneity of the variances and mean scores of the two groups on the WM posttests (Table 3).

Table 3. T-tests for comparing the mean scores of the explicit and implicit groups on the pretests and posttests

\begin{tabular}{|c|c|c|c|c|c|}
\hline \multirow{2}{*}{ Tests } & \multicolumn{2}{|c|}{$\begin{array}{c}\text { Levene's } \\
\text { test }\end{array}$} & \multicolumn{3}{|c|}{ t-test } \\
\cline { 2 - 6 } & $\mathrm{F}$ & sig. & $\mathrm{T}$ & $\mathrm{df}$ & $\begin{array}{c}\text { Sig. (2- } \\
\text { tailed) }\end{array}$ \\
\hline $\begin{array}{c}\text { Grammar } \\
\text { Pre-Test }\end{array}$ & 1.710 & .202 & .56 & 28 & .575 \\
\hline $\begin{array}{c}\text { Grammar } \\
\text { Post-Test }\end{array}$ & 6.960 & .013 & .70 & 23 & .485 \\
\hline PL Pre-Test & 1.676 & .206 & 1.03 & 28 & .310 \\
\hline PL Post-Test & 7.550 & .010 & 2.16 & 18 & .044 \\
\hline OPI Pre-Test & .003 & .957 & 1.25 & 28 & .219 \\
\hline $\begin{array}{c}\text { OPI task } \\
\text { Post-Test }\end{array}$ & 2.600 & .118 & 2.89 & 28 & .007 \\
\hline $\begin{array}{c}\text { Visuospatial } \\
\text { Pre-Test }\end{array}$ & .020 & .889 & 1.63 & 28 & .113 \\
\hline $\begin{array}{c}\text { Visuospatial } \\
\text { Post-Test }\end{array}$ & 6.405 & .017 & 4.73 & 21 & .000 \\
\hline WM Pre-Test & 3.809 & .061 & .069 & 28 & .945 \\
\hline $\begin{array}{c}\text { WM Post- } \\
\text { Test }\end{array}$ & 5.798 & .023 & 3.050 & 28 & .005 \\
\hline
\end{tabular}

With $\mathrm{F}(2,28)=7.550, p=.010$ (two-tailed) for the PL posttest; $\mathrm{F}(2,28)=2.60, p=.118$ (two-tailed) for the OPI posttest; $\mathrm{F}(2,28)=6.405, p=.017$ (twotailed) for the visuospatial posttest, and $\mathrm{F}(2,28)=$ $5.798, p=.023$ (two-tailed) for the WMC posttest (total), it was decided that the variances of the two groups were homogenous on the memory posttests. With $\mathrm{t}(18)=2.16, p=0.04$ (two-tailed) for the PL test; $\mathrm{t}(28)=2.89, p=0.007$ (two-tailed) for the OPI test, $\mathrm{t}(21)=4.73, p=0.000$ (two-tailed) for the visuospatial sketchpad test, and $\mathrm{t}(28)=3.05, p=$ 
0.005 (two-tailed) for the total WM posttest, it was decided that there were significant differences between the means of the two groups on all the three measures of the components of WMC. In other words, the implicit group had significantly outperformed the explicit group on all the three tests of WMC.

In the last phase of the study, a grammar posttest was administered to measure the participants' grammatical knowledge after the treatment. The result of the Levene's test revealed that the variances of the two groups on this test were homogeneous $(\mathrm{F}(2,23)=6.960, p=0.013$ (two-tailed)). Similarly, with $\mathrm{t}(23)=0.709, \quad p=0.485$ (two-tailed), no statistically significant difference was observed between the two groups' mean scores on the grammar post-test at the end of the study. Hence, it was concluded that, although both groups had improved their grammatical knowledge, neither of the two teaching methods was superior to the other in producing better results.

\section{Conclusion}

The aim of the present study was to investigate the effects of implicit and explicit grammar instruction on expanding EFL learners' level of WMC and increasing their grammatical knowledge. The findings of this study revealed that implicit grammar instruction can contribute to WMC expansion. They demonstrated that WM operations can take place outside of conscious awareness and without intention. Although both groups had increased their WMC, the significant changes in terms of WMC were only observed in the implicit group. This could be attributed to the students' reliance on their memory in order to keep and process the data more deeply in order to discover the rules themselves. As mentioned before, there was no explanation in this group, and the participants had to rely on their own mental resources to make inferences about the target grammatical rules. Such practice might have resulted in their greater use of WM and creating connections among the received bits of data for further processing. This finding, however, was in conflict with that of Ercetin and Alptekin [14]. They found that the relationship between WM and explicit knowledge is very strong, and there is no significant relationship between implicit knowledge and WMC.

In line with previous research [1], the results of this study showed a strong relationship between phonological loop and executive control and learning grammar. As mentioned before, working memory includes both storage and processing of information. Furthermore, grammar learning depends on much more than just memorizing items. It is also the process of abstracting patterns from input. Grammatical patterns involve abstracting the relations between vocabulary items and identifying their functional significance. These more complicated patterns, therefore, demand more processing capacities. In the implicit class, the participants were simply exposed to the structures in a sentence context. This more "naturalistic" way of learning requires much more effort on the learners' part and may also require a different type of language processing. The participants did not receive explicit metalinguistic feedback on their output and just heard the correct form in the flow of speech. To learn from this process, they had to keep the sentence in memory while actively comparing it to the feedback they would hear. Such operations, involving both storage and processing must be heavily dependent on WM capacities.

Randall [4] argues that the most serious challenge faced by ESL/EFL learners is that of achieving the level of automaticity that first language users achieve. The analysis of the effects of WMC on language learning has highlighted the complexities involved in all levels of processing from raw features detection to semantic and syntactic processing. Thus the establishment of connections between WM and LTM are crucial. The more automatic these links are, the less capacity will be consumed in the WM and the more the central executive will be able to concentrate on different sources of information for the comprehension of messages or on higher order cognition [4].

SLA/FLA researchers have tended to focus on the PL, the portion responsible for the auditory information, and central executive, which is responsible for regulating the attention. This distinction is important in FLA because learning a foreign language is a cognitive task which requires the maintenance of the input, as well as processing the input and searching for appropriate connections in the long-term memory. However, language use becomes automatic after the language has been acquired; hence, WM is critical at the beginning stages, but might not be so in the advanced levels [8].

A review of $\mathrm{L} 2$ acquisition and instruction processes reveals that inductive explicit grammar instruction is a viable method, which can generate positive learning outcomes [20]. However, regarding the second research question, it was observed that both methods, implicit and explicit, had equally contributed to improving the students' grammatical knowledge. Therefore, some other factors might be at work in creating knowledge differences among students studying grammar implicitly or explicitly. 
In general, WMC is helpful in many ways for grammatical problem solving. WMC-related differences may result from differences in encoding or retrieval of grammar-related knowledge in LTM, in the ability to deal with interference from competing information, and in the ability to limit distraction from irrelevant problem features.

\section{Future work}

As it is usually the case, the results of this study warrant replication in other contexts with different samples, languages, experimental conditions. Here, the researchers demonstrated that implicit grammar instruction can expand FL learners' WMC. However, it is important to emphasize that this result must be interpreted cautiously because the required data were compiled from only two intact classes over a short period of time (16 sessions). Similar studies carried out over a longer period of time are necessary to confirm the results of this research.

Future research should also address the questions of whether we know about all the components of working memory, or how the views of the functions of working memory might change in the future. Varying the ways in which grammar is taught and feedback is given are also important to determining whether the findings of this study apply across different learning conditions.

One additional question for further research concerns the degree to which the observed interaction between WMC and method of grammar instruction is generalizable to other skills such as reading, speaking, listening, vocabulary, and pronunciation.

In the present study, three tests (Forward Digit Span, Paired Associates, and OPI) were used to measure the participants' WMC. Other studies can be carried out using other measures of WMC.

\section{References}

[1] A. Juffs and M. Harrington, "Aspects of Working Memory in L2 Learning", Language Teaching, vol. 44 (2), Cambridge University Press, 2011, pp. 137-166.

[2] B.T. Tulbure and I. Siberescu, "Cognitive Training Enhances Working Memory Capacity in Healthy Adults: A Pilot Study", Social and Behavioral Sciences, vol. 78, Romania, 2014, pp.175 - 179.

[3] Carroll, D.W., Psychology of Language, Thomson Wadworth, Canada, Toronto, 2008.

[4] Randall, M., Memory, Psychology, and Second Language Learning, John Benjamin's Publishing Company, Amsterdam/Philadelphia, 2007.
[5] J.A. Englund et.al. "Development and Evaluation of an Online, Multicomponent Working Memory Battery", Assessment, vol. 44, Sage Publications, 2014, pp.137166.

[6] Z. Weng, "Theorizing and Measuring Working Memory in First and Second Language Research", Language Teaching Research, vol. 47, Cambridge University Press, 2014, pp. 174-190.

[7] Atkinson, D., Alternative Approaches to Second Language Acquisition, Routledge, London and New York, 2011.

[8] K. B. Nielson, "Can planning time compensate for individual differences in working memory capacity", Language Teaching Journal, vol. 18(3), 2014, 272-293.

[9] Nassaji, H. and S. Fotos, Teaching Grammar in Second Language Learning, Routledge, New York and London, 2011.

[10] J. M. Norris and L. Ortega, "Effectiveness of L2 Instruction: A Research Synthesis and Quantitative Meta-analysis", Language Learning, 2000, pp. 417-528.

[11] A. D. Baddeley and G. J. Hitch, "Working Memory", The Psychology of Learning and Motivation, vol. 8, G.H. Bower (ed.), Academic Press, London, 1974.

[12] O'Brien et.al. "Phonological Memory and Lexical, Narrative, and Grammatical Skills in Second Language Oral Production by Adult Learners", Applied Psycholinguistics, vol.27, United States of America, 2006, pp. 377-402.

[13] K. I. Martin and N. Ellis, "The Roles of Phonological Short Term Memory and Working Memory in L2 Grammar and Vocabulary Learning", Studies in Second Language Acquisition, vol.34 (3), 2012, pp. 379-413.

[14] G. Ercetin and C. Alptekin, "The Explicit/Implicit Knowledge Distinction and Working Memory: Implications for Second-Language Reading Comprehension", Applied Psycholinguistics, vol. 34, 2013, 727-753.

[15] C. A. Sanchez et. al., "Assessing WMC in Non-Native Language Setting", Learning and Individual Differences Journal, vol. 20, Elsevier Inc., 2010, pp. 488-493.

[16] H. S. C. Thompson, "Establishing the Reliability and Validity of a Computerized Assessment of Children's Working Memory for Use in Group Settings", Journal of Psychoeducational Assessment, vol. 32(1), Sage Publications, 2014, pp. 15-26.

[17] Long. M. and C. Doughty, The Handbook of Language Teaching, John Wiley \& Sons, Ltd. Publications, United Kingdom, 2009.

[18] R. Ellis, "Current Issues in Teaching Grammar: An SLA Perspective", TESOL Quarterly, 40(1), 2006, 83107. 
[19] R. Ellis, "Implicit and Explicit Knowledge in Second Language Learning, Testing and Teaching", Multilingual Matters, Bristol, Buffalo, Toronto, 2009.

[20] M. Caprario, "Guided Discovery Grammar Instruction: A Review of the Literature with Original Teaching Materials", MA TESOL Collection, 2013.

[21] N. Spada, "Beyond Form-Focused Instruction: Reflections on Past, Present and Future Research", Language Teaching, Cambridge University Press, vol. 44(2), 2011, pp. 225-236. 